\title{
NOD receptor and TLR9 modulation in severe acute pancreatitis-induced intestinal injury
}

\author{
YUPENG YAN ${ }^{1}$, BIN LU $^{2}$, PENGYANG $\mathrm{LI}^{3}$ and $\mathrm{JI}_{\mathrm{WANG}}{ }^{1}$ \\ ${ }^{1}$ Intensive Care Unit, China Meitan General Hospital, Beijing 100028; ${ }^{2}$ Department of Anesthesiology, Beijing Hospital \\ of Traditional Chinese Medicine; ${ }^{3}$ Department of Orthopedics, Dongzhimen Hospital, Beijing 100010, P.R. China
}

Received August 1, 2016; Accepted May 9, 2017

DOI: $10.3892 / \mathrm{mmr} .2017 .7661$

\begin{abstract}
Severe acute pancreatitis (SAP) has a rapid onset and may cause multiple organ dysfunction syndrome (MODS), which has high mortality. Nucleotide binding oligomerization domain (NOD) receptor and Toll-like receptor 9 (TLR9), a pattern recognition receptor in innate immunity, are involved in inflammation, immunity and pathogen recognition. The role and mechanism of the NOD receptor and TLR9 in early MODS of SAP-induced intestinal injury, however, remain unclear. Wistar rats were divided into control, SAP, TLR9 inhibitor and NOD receptor activation groups. Reverse transcription-quantitative polymerase chain reaction was used to analyze the expression of TLR9, NOD1 and NOD2 in the experimental treatment groups. Serum amylase, creatinine and alanine aminotransferase indices were measured, ELISA was used to determine the expression of tumor necrosis factor- $\alpha$ $(\mathrm{TNF}-\alpha)$ and interleukin-1 $\beta$ (IL-1 $\beta$ ) and western blot analysis was used to assess nuclear factor (NF)- $\kappa \mathrm{B}$ expression levels in intestinal tissues. Reactive oxygen species (ROS) levels and superoxide dismutase (SOD) activity were quantified by spectrometry. SAP and NOD receptor activation groups exhibited significantly elevated TLR9, NOD1, NOD2, TNF- $\alpha$, IL-1 $\beta$ and nuclear factor (NF)- $\mathrm{\kappa B}$ levels compared with the control group. Furthermore, ROS production was increased, SOD activity was decreased and higher serum indices were exhibited, compared with the control group. The NOD receptor group presented more significant differences compared with the SAP group. The TLR9 inhibitor group exhibited opposite effects, with markedly decreased TLR9, NOD1, NOD2, TNF- $\alpha$, IL-1 $\beta$ and NF- $\kappa \mathrm{B}$ levels. The TLR9 inhibitor group also presented reduced ROS production, increased SOD activity and lower serum indexes compared to the SAP group. The present study therefore indicated that NOD receptor and TLR9 may modulate
\end{abstract}

Correspondence to: Dr Bin Lu, Department of Anesthesiology, Beijing Hospital of Traditional Chinese Medicine, 23 Art Museum Backstreet, Dongcheng, Beijing 100010, P.R. China

E-mail: binluqwe@sina.com

Key words: nucleotide oligomerization domain, receptor, toll-like receptor 9 , severe acute pancreatitis, nuclear factor- $\mathrm{\kappa} B$ the inflammatory response and further impact upon intestinal injury of SAP, via the regulation of NF- $\mathrm{kB}$ expression and the oxidation/antioxidation balance, suggesting therapeutically targeting NOD receptor and TLR9 might be a useful approach for the treatment of severe acute pancreatitis.

\section{Introduction}

Acute pancreatitis (AP) is commonly observed in clinics (1). Severe acute pancreatitis (SAP) can cause necrosis of peri-pancreatic tissues, injury and dysfunction of several organs, thus rapidly aggravating the patient's condition. Due to the lack of effective and specific treatment, SAP has an unfavorable prognosis and a high mortality rate (2). SAP is frequently caused by a secondary bacterial infection, and can cause injury to the intestinal mucosal structure or functioning, thus disrupting the intestinal barrier and resulting in systemic inflammatory response syndrome (SIRS) and multiple organ dysfunction syndrome (MODS) (3,4). During SAP, the mucosal barrier becomes damaged, which increases the permeability of the intestinal tract and allows the release of gut bacteria, thus resulting in intestinal infection. Bacterial contamination can cause the body to release large amounts of inflammatory mediators and cytokines, causing endotoxemia and further early injuries related to MODS (5). During the occurrence and progression of AP, intestinal mucosal barrier injury is a critical factor following intestinal injury; the inhibition of SAP-related mucosal barrier injuries is a primary target for the prevention and treatment of early MODS.

The innate immune system is the initial line of defense against microbial invasions that cause intestinal mucosal injury (6). During this process, pattern recognition receptors (PRR) serve an important role in defending against infection (7). The extracellular PRR, Toll-like receptor (TLR) and the intracellular PRR, nucleotide oligomerization domain (NOD) receptor, are two important members of the innate immune system for recognizing and fighting against microbial pathogens $(8,9)$. NOD-like receptors (NLRs) display highly conserved structures (10) and participate in recognition and defense against microbial pathogens. Furthermore, they modulate the homeostasis of intestinal symbiotic microbes (11), thus exhibiting a bifunctional role. As one of the transmembrane PRRs involved in pathogen recognition, TLRs serve important roles in signal transduction, phagocytosis and cell apoptosis 
during acute inflammation $(12,13)$. A previous study correlated TLR4 expression with the pathogenesis of AP (14), however, TLR9 is indispensable for inflammation, immunity and pathogen recognition $(15,16)$. The role of TLR9 in AP and its interaction with NOD, or other related mechanisms, has not currently been elucidated. Therefore, the present study aimed to investigate the role of the NOD receptor and TLR9 in MODS-induced intestinal injury during early SAP. As NOD receptor and TLR9 are both play an important role in microbial pathogens recognition and inflammation, and the close association of TLR9 with AP, the present study investigated the role of TLR9 and NOD receptor in rats with SAP through blocking TLR9 or activating the NOD receptor.

\section{Materials and methods}

Experimental animals. A total of 40 healthy male Wistar rats (age, 2 months; body weight, $250 \pm 20 \mathrm{~g}$ ) were purchased from Laboratory Animal Unit of Chinese Medical Sciences University (Shenyang, China) and were kept in a specific-pathogen-free grade facility. The room temperature was maintained at $21 \pm 1^{\circ} \mathrm{C}$ and the relative humidity was maintained at 50-70\%. Animals were kept on a 12-h light/dark cycle with free access to food and water. All procedures were approved by the Animal Ethics Committee of China Meitan General Hospital (Beijing, China).

Reagents and instruments. Sodium taurocholate, glutamate-meso-diaminopimelic acid (DAP), muramic acid dipeptide (MDP) and chloroquine were purchased from Sigma-Aldrich (Merck KGaA, Darmstadt, Germany). Polyvinylidene difluoride membrane was purchased from Pall Life Sciences (Port Washington, NY, USA). Western blotting lysis buffer was purchased from Beyotime Institute of Biotechnology (Haimen, China). Enhanced Chemiluminescence (ECL) reagent was purchased from Amersham (GE Healthcare Life Sciences, Little Chalfont, UK). Rabbit anti-rat nuclear factor (NF)- $\kappa \mathrm{B}$ monoclonal antibody (cat. no. 4764) and horseradish peroxidase-labelled IgG secondary antibody (cat. no. 7074) were purchased from Cell signaling Technology, Inc. (Danvers, MA, USA). Tumor necrosis factor (TNF)- $\alpha$ (cat. no. RTA00) and interleukin (IL)-1 $\beta$ (cat. no. RLB00) ELISA kits were purchased from R\&D Systems, Inc. (Minneapolis, MN, USA). The TRIzol reagent for RNA extraction, reverse transcription (RT) cDNA first chain synthesis kit and superoxide dismutase (SOD) assay kit were purchased from Nanjing Jiancheng Bioengineering Institute (Nanjing, China). The surgical microscope was purchased from Suzhou Sunan Zimmered Medical Instrument Co., Ltd. (Suzhou, China). The microplate reader was purchased from BD Biosciences (Franklin Lakes, NJ, USA). The Gene Amp PCR System 2400 DNA cycler was purchased from PerkinElmer, Inc. (Waltham, MA, USA). Other common reagents were purchased from Sangon Biotech Co., Ltd. (Shanghai, China).

Animal grouping and treatment. Wistar rats were randomly divided into four groups ( $n=20 /$ group). The four groups were: Control group, which received an equal volume of saline inside the bile duct; SAP model group; TLR inhibitor group, which received an intraperitoneal injection of the TLR9 inhibitor chloroquine, following SAP model induction; and NOD receptor activation group, which received an intraperitoneal injection of the NOD receptor agonists MDP and DAP, following SAP model induction.

Rat SAP model preparation. Animals were fasted for $12 \mathrm{~h}$, and subsequently anesthetized using $10 \%$ chloral hydrate via intraperitoneal injection. The animals were secured onto the stage, and a median incision was made in the upper abdomen to expose the duodenum and biliary pancreatic duct, which was doubly clipped on the proximal site of the hepatic portal vein using a non-invasive artery clip. A retrograde puncture was made on the biliary pancreatic duct via the duodenal papilla, followed by fixation using non-invasive artery clips. Freshly prepared 5\% sodium taurocholate solution was applied into the biliary pancreatic duct at $0.1 \mathrm{ml} / \mathrm{min}$ velocity to reach an internal concentration of $0.1 \mathrm{mg} / 100 \mathrm{~g}$ body weight. The duct was then clipped for $5 \mathrm{~min}$ to completely immerse the pancreatic lobes in sodium taurocholate solution. The artery clip was then released to reperfuse the duodenum, followed by abdominal suture. In the control group, an equal volume of saline was applied instead of sodium taurocholate. The TLR9 inhibitor group was treated with an intraperitoneal injection of $10 \mathrm{mM} / \mathrm{kg}$ TLR9 inhibitor chloroquine. The NOD receptor activation group was treated with an intraperitoneal injection of $10 \mathrm{mM} / \mathrm{kg}$ MDP and $10 \mathrm{mM} / \mathrm{kg}$ DAP. The injections were administered immediately after the SAP operation.

Sample collection. Rats were anaesthetized with ketamine-zylazine and blood samples were collected from the abdominal aorta using vacuum tubes at $12 \mathrm{~h}$ after SAP. Blood was incubated at room temperature for $30 \mathrm{~min}$, followed by $4^{\circ} \mathrm{C}$ centrifugation at $1,200 \mathrm{x}$ g for $10 \mathrm{~min}$ to collect the supernatant. Serum was frozen at $-20^{\circ} \mathrm{C}$ for further use. Injured intestinal tissues were collected from all groups and stored at $-80^{\circ} \mathrm{C}$.

Serology indexes assay. An automatic biochemical analyzer (AU680, Beckman Coulter) was used to test the serum amylase (AMY), creatinine $(\mathrm{Cr})$ and alanine aminotransferase (ALT) levels according to manufacturer's protocol.

ELISA test for serum levels of inflammatory factors TNF- $\alpha$ and $I L-1 \beta$. Serum samples were tested for inflammatory factors including TNF- $\alpha$ and IL-1 $\beta$ levels using ELISA kits, following the manufacturer's protocol. In brief, $50 \mu 1$ serially diluted standards were added into a 96-well plate, and test samples $(50 \mu \mathrm{l})$ were applied in triplicates and incubated for $2 \mathrm{~h}$. Following gentle washing (5 times) with washing buffer and a $30 \mathrm{sec}$ vortex, $50 \mu \mathrm{l}$ enzyme labeling reagent was added into each well and incubated at $37^{\circ} \mathrm{C}$ for $30 \mathrm{~min}$. Following a further 5 washes, chromogenic substrates $\mathrm{A}$ and $\mathrm{B}\left(50 \mu \mathrm{l}\right.$ each) were added and developed in the dark at $37^{\circ} \mathrm{C}$ for $10 \mathrm{~min}$. The reaction was quenched with $50 \mu \mathrm{l}$ stopping buffer. A microplate reader was used to measure absorbance values at $450 \mathrm{~nm}$. A standard curve was plotted based on the standard concentrations and respective optical density (OD) values, followed by calculation of the sample concentrations using the sample OD values. 
Table I. Primer sequences used for quantitative polymerase chain reaction.

\begin{tabular}{lll} 
Target gene & \multicolumn{1}{c}{ Forward primer $\left(5^{\prime}-3^{\prime}\right)$} & \multicolumn{1}{c}{ Reverse primer $\left(5^{\prime}-3^{\prime}\right)$} \\
\hline GADPH & AGTGCCAGCCTCGTCTCATAG & ACTTGCAACTTGCCGTGGGTAG \\
TLR9 & CTCATCTAAGCGGAACAATGG & GCACATTCTCTCCGTAGCG \\
NOD1 & TAAGCATCTAAGGAACGGAATG & ACATTCTCTTCATCTA \\
NOD2 & TCATAGCCTCCATCT & ACTTGCACTTGCGGG
\end{tabular}

TLR9, Toll-like receptor 9; NOD, nucleotide oligomerization domain receptor.

Reverse transcription-quantitative polymerase chain reaction (RT-qPCR) for TLR9, NOD1 and NOD2 mRNA expression in $S A P$ intestines. Intestinal tissues were collected and rinsed in PBS. Tissues were homogenized in liquid nitrogen and total RNA was extracted using TRIzol reagent. cDNA was synthesized using cDNA first chain synthesis kit. A fluorescent qPCR kit (Verso 1-Step RT-qPCR SYBR Green kit; Thermo Fisher Scientific, Inc., Waltham, MA, USA) was used to collect data and determine the $\mathrm{Cq}$ value, with reference to GAPDH. PCR amplification was performed in a total volume of $20 \mu 1$, including $10 \mu \mathrm{l}$ SYBR Green qPCR Super Mix, $0.5 \mu 1$ forward primer $(10 \mu \mathrm{M}), 0.5 \mu 1$ reverse primer $(10 \mu \mathrm{M}), 5 \mu \mathrm{l}$ cDNA and $4 \mu \mathrm{l}$ sterile water under the following conditions: $52^{\circ} \mathrm{C}$ for $1 \mathrm{~min}$, followed by 35 cycles of $90^{\circ} \mathrm{C}$ denaturation for $30 \mathrm{sec}$, $58^{\circ} \mathrm{C}$ annealing for $50 \mathrm{sec}$ and $72^{\circ} \mathrm{C}$ elongation for $35 \mathrm{sec}$. Primers are presented in Table I. The relative expression level was determined using the $2^{\text {- DDCq }}$ method (17).

Western blotting for $N F-\kappa B$ protein expression. Total proteins were extracted from intestinal tissues after homogenization on liquid nitrogen, mixed with lysis buffer (Beyotime Institute of Biotechnology) for 15-30 min and incubated on ice. Using ultrasonic rupture ( $5 \mathrm{sec}, 4$ times) and centrifugation $(10,000 \mathrm{x} \mathrm{g}$ for $15 \mathrm{~min})$ at $4^{\circ} \mathrm{C}$, proteins were collected and stored at $-20^{\circ} \mathrm{C}$ for subsequent western blotting. Proteins (20 mg/lane) were separated by 10\% SDS-PAGE, and were transferred to PVDF membranes using the semi-dry method. Non-specific binding sites were blocked by $5 \%$ non-fat milk powder for $2 \mathrm{~h}$. The membrane was incubated with anti-NK- $\mathrm{B}$ monoclonal antibody $(1: 1,000)$ at $4{ }^{\circ} \mathrm{C}$ overnight. Goat anti-rabbit IgG (1:2,000) was subsequently added for $30 \mathrm{~min}$ at room temperature. Following $0.1 \%$ (v/v) PBS-Tween washing and ECL development for $1 \mathrm{~min}$, the membrane was exposed to X-ray film. An image analyzing system (ImageQuant LAS 500, GE Healthcare Life Sciences) and Quantity One software version 4.3.0 (Bio-Rad Laboratories, Inc., Hercules, CA, USA) was used to scan the X-ray films and to detect the density of bands, from repeated experiments $(n=4)$.

SOD activity assay. SOD activity was tested in intestinal tissues using a SOD activity assay kit, according to the manufacturer's protocol. In brief, tissue homogenate samples prepared as aforementioned were denatured at $95^{\circ} \mathrm{C}$ for $40 \mathrm{~min}$, and centrifuged at $1,500 \mathrm{x} \mathrm{g}$ for $10 \mathrm{~min}$ at $4^{\circ} \mathrm{C}$. An ethanol-chloroform mixture $(5: 3, \mathrm{v} / \mathrm{v})$ was used to extract the ethanol phase in the homogenate, to determine the total SOD activity.

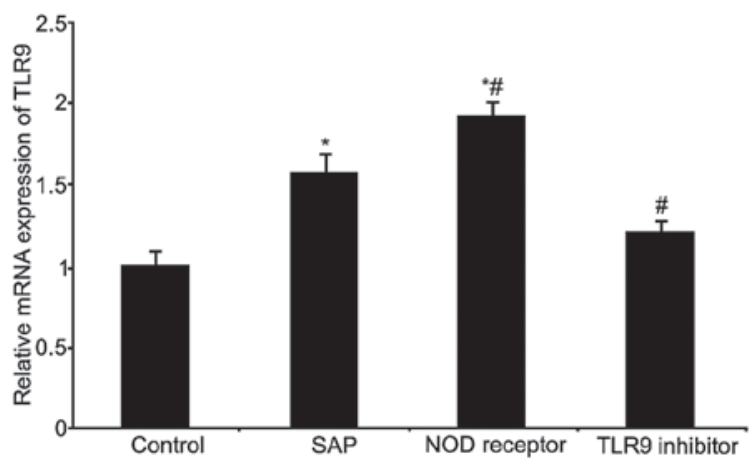

Figure 1. Effects of TLR9 and NOD receptor modulation on TLR9 mRNA expression in SAP intestinal tissues. ${ }^{*} \mathrm{P}<0.05$ vs. control group; ${ }^{\prime \prime} \mathrm{P}<0.05$ vs. SAP group. SAP, severe acute pancreatitis; TLR9, Toll-like receptor 9; NOD, nucleotide oligomerization domain receptor.

Reactive oxygen species (ROS) content assay. Intestinal tissue homogenates were denatured at $95^{\circ} \mathrm{C}$ for $40 \mathrm{~min}$, cooled in tap water, and centrifuged at $1,500 \mathrm{x} \mathrm{g}$ for $10 \mathrm{~min}$ at $4^{\circ} \mathrm{C}$. Homogenates were incubated at $37^{\circ} \mathrm{C}$ in $2^{\prime}, 7^{\prime}$-dichlorofluorescein diacetate for $15 \mathrm{~min}$. Following centrifugation at 4,000 x g for $15 \mathrm{~min}$ at room temperature, the precipitates were re-suspended in sterilized PBS buffer, and incubated at $37^{\circ} \mathrm{C}$ for $60 \mathrm{~min}$. Spectrometry was used to detect the ROS levels at a wavelength of $520 \mathrm{~nm}$, and data were expressed as a ROS production percentage.

Statistical analysis. SPSS v16.0 software (SPSS, Inc., Chicago, IL, USA) was used to analyze all data. Measurements were expressed as the mean \pm standard deviation. One-way analysis of variance with Newman-Keuls multiple comparison post-hoc analysis was used to compare the means across groups. $\mathrm{P}<0.05$ was considered to indicate a statistically significant difference.

\section{Results}

TLR9 expression in rat intestinal tissues. RT-qPCR was used to measure TLR9 mRNA expression levels in rat intestinal tissues from all treatment groups (Fig. 1). The results indicated significantly elevated levels of TLR9 mRNA in the SAP and NOD receptor activation groups $(\mathrm{P}<0.05$, compared with the control group); the NOD receptor activation group exhibited the greatest increase of TLR9 mRNA $(\mathrm{P}<0.05$, compared with the SAP group). The TLR9 inhibitor group significantly 
Table II. Serology indices of SAP rats.

\begin{tabular}{lcccc}
\hline Index & Control & SAP & NOD receptor & TLR9 inhibitor \\
\hline AMY(U/l) & $1,520 \pm 216$ & $6,659 \pm 232^{\mathrm{a}}$ & $7,617 \pm 378^{\mathrm{a}, \mathrm{b}}$ & $3,159 \pm 345^{\mathrm{a}, \mathrm{b}}$ \\
ALT (U/l) & $118 \pm 13.2$ & $342 \pm 31.2^{\mathrm{a}}$ & $451 \pm 12.1^{\mathrm{a}, \mathrm{b}}$ & $186 \pm 22.4^{\mathrm{a}, \mathrm{b}}$ \\
Cr (U/l) & $32 \pm 2.1$ & $97 \pm 3.6^{\mathrm{a}}$ & $121 \pm 6.6^{\mathrm{a}, \mathrm{b}}$ & $51 \pm 4.3^{\mathrm{a}, \mathrm{b}}$ \\
\hline
\end{tabular}

${ }^{\mathrm{a}} \mathrm{P}<0.05$ vs. control group; ${ }^{\mathrm{b}} \mathrm{P}<0.05$ vs. SAP group. SAP, severe acute pancreatitis; NOD, nucleotide oligomerization domain receptor; TLR9, Toll-like receptor 9; AMY, amylase; ALT, alanine amino transferase; Cr, creatinine.

inhibited TLR9 mRNA expression $(\mathrm{P}<0.05$, compared with the SAP group).

NOD1 and NOD2 expression change in rat intestinal tissues. RT-qPCR was performed to measure the mRNA levels of NOD1 and NOD2 in rat intestinal tissues from all treatment groups (Fig. 2). The results demonstrated significantly elevated NOD1 and NOD2 mRNA expression levels in the SAP model and NOD receptor activation groups $(\mathrm{P}<0.05$, compared with the control group); the NOD receptor activation group exhibited a stronger increase of NOD1 and NOD2 mRNA ( $\mathrm{P}<0.05$, compared with the SAP group). The TLR9 inhibitor group significantly inhibited NOD1 and NOD2 mRNA expression ( $\mathrm{P}<0.05$, compared with the SAP group). These results indicated an inter-regulation between TLR9 and NOD in SAP-induced intestinal injury.

Serology index analysis. Serology indices were measured $12 \mathrm{~h}$ following SAP in all treatment groups (Table II). The results indicated significantly elevated AMY, Cr and ALT in the SAP and NOD receptor activation groups $(\mathrm{P}<0.05$, compared with the control group); the NOD receptor activation group exhibited the greatest increase of the measured indices $(\mathrm{P}<0.05$, compared with the SAP group). Treatment with the TLR9 inhibitor significantly inhibited the elevation of these serology indices ( $\mathrm{P}<0.05$, compared with the SAP group), however, the measured levels were higher than the control group. These results demonstrated that modulation of the NOD receptor and TLR9 may improve the serology indices in the early phase of MODS related with SAP.

Effects of TLR 9 inhibition and NOD receptor activation on the levels of serum inflammatory factors TNF- $\alpha$ and IL-1 . ELISA tests were used to investigate the effects of TLR9 inhibition and NOD receptor activation on the serum levels of the inflammatory factors TNF- $\alpha$ and IL-1 $\beta$ (Fig. 3). The results indicated significantly elevated levels of the serum inflammatory factors TNF- $\alpha$ and IL- $1 \beta$ in the SAP and NOD receptor activation groups $(\mathrm{P}<0.05$, compared with the control group), and the NOD receptor activation group exhibited the greatest increase of these factors $(\mathrm{P}<0.05$, compared with the SAP group). The TLR9 inhibitor group significantly inhibited secretion of these inflammatory factors $(\mathrm{P}<0.05$, compared with the SAP group). These results demonstrated that modulation of the NOD receptor and TLR9 may ameliorate SAP-induced intestinal injury by altering the secretion of serum inflammatory factors.

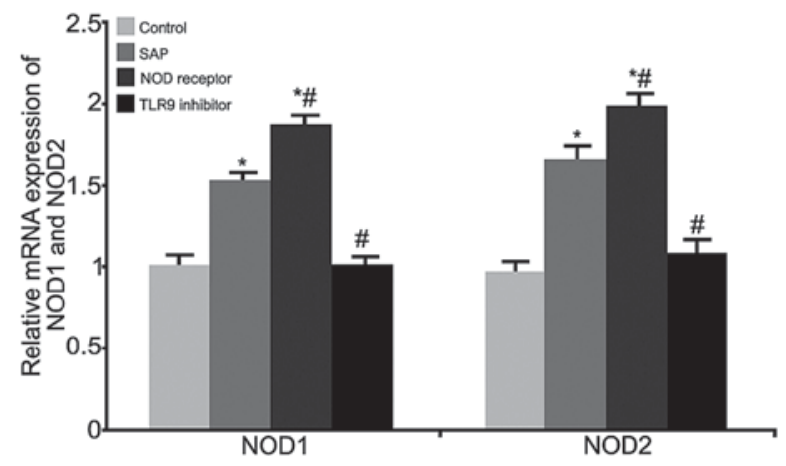

Figure 2. Effects of TLR9 and NOD receptor modulation on NOD1 and NOD2 mRNA expression in SAP intestinal tissues. ${ }^{*} \mathrm{P}<0.05$ vs. control group; ${ }^{\#} \mathrm{P}<0.05$ vs. SAP group. SAP, severe acute pancreatitis; TLR9, Toll-like receptor 9; NOD, nucleotide oligomerization domain receptor.

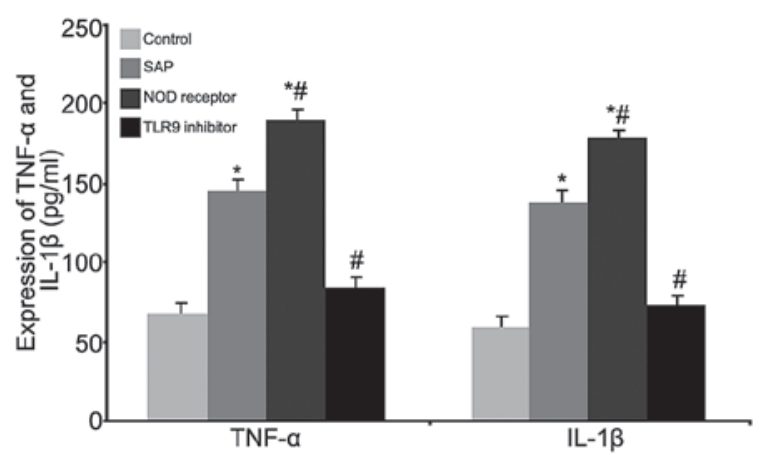

Figure 3. Effects of TLR9 and NOD receptor modulation on serum levels of inflammatory factors TNF- $\alpha$ and IL- $1 \beta$ in SAP. ${ }^{*} \mathrm{P}<0.05$ vs. control group; ${ }^{\#} \mathrm{P}<0.05$ vs. SAP group. SAP, severe acute pancreatitis; TLR9, Toll-like receptor 9; NOD, nucleotide oligomerization domain receptor; TNF- $\alpha$, tumor necrosis factor $\alpha$; IL-1 $\beta$, interleukin $1 \beta$.

Effects of TLR9 inhibition and NOD receptor activation on the intestinal expression of $N F-\kappa B$. Western blot analysis was used to investigate the effect of TLR9 inhibition and NOD receptor activation on intestinal NF- $\mathrm{KB}$ expression (Fig. 4). The results indicated significantly elevated NF- $\kappa \mathrm{B}$ expression in the SAP and NOD receptor activation groups $(\mathrm{P}<0.05$, compared with the control group); the NOD receptor activation group exhibited a stronger increase of NF- $\kappa \mathrm{B}$ expression $(\mathrm{P}<0.05$, compared with the SAP group). The TLR9 inhibitor group significantly inhibited NF- $\kappa$ B expression levels $(\mathrm{P}<0.05$, compared with the SAP group). These results indicated that the NOD receptors 
Table III. Effects of TLR9 and NOD receptor on oxidative stress indices of pancreatic tissues.

\begin{tabular}{lrccc}
\hline $\begin{array}{l}\text { Parameter } \\
\text { (relative value) }\end{array}$ & Control & SAP & $\begin{array}{c}\text { NOD } \\
\text { receptor }\end{array}$ & $\begin{array}{c}\text { TLR9 } \\
\text { inhibitor }\end{array}$ \\
\hline ROS & $56 \pm 14$ & $259 \pm 31^{\mathrm{a}}$ & $289 \pm 67^{\mathrm{a}, \mathrm{b}}$ & $162 \pm 42^{\mathrm{a}-\mathrm{c}}$ \\
SOD & $137 \pm 23$ & $85 \pm 12^{\mathrm{a}}$ & $58 \pm 6^{\mathrm{a}, \mathrm{b}}$ & $117 \pm 21^{\mathrm{a}-\mathrm{c}}$ \\
\hline
\end{tabular}

${ }^{\mathrm{a}} \mathrm{P}<0.05$ vs. control group; ${ }^{\mathrm{b}} \mathrm{P}<0.05$ vs. SAP group; ${ }^{\mathrm{c}} \mathrm{P}<0.05$ vs. NOD receptor group. SAP, severe acute pancreatitis; TLR9, Toll-like receptor 9; NOD, nucleotide oligomerization domain receptor; ROS, reactive oxygen species; $\mathrm{SOD}$, superoxide dismutase.

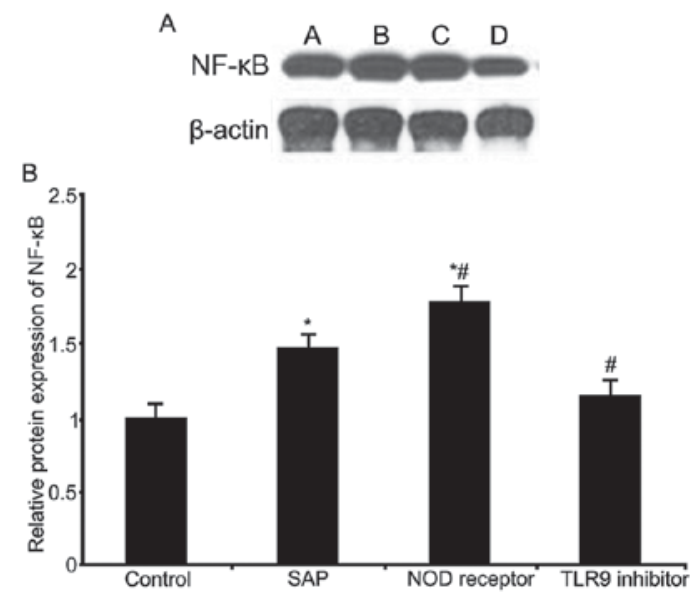

Figure 4. Effects of TLR9 and NOD receptor modulation on intestinal expression of NF- $\mathrm{kB}$ in SAP. (A) Western blot analysis. A, control group; B, SAP group; C, NOD receptor group; D, SAP group. (B) Semi-quantitation of western blot analysis. ${ }^{~} \mathrm{P}<0.05$ vs. control group; ${ }^{\#} \mathrm{P}<0.05$ vs. SAP group. SAP, severe acute pancreatitis; TLR9, Toll-like receptor 9; NOD, nucleotide

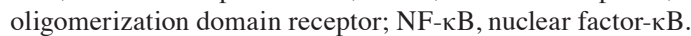

and TLR9 may modulate SAP-induced intestinal injury, via the regulation of intestinal NF- $\mathrm{BB}$ expression.

Effects of TLR9 inhibition and NOD receptor activation on oxidative stress. ROS levels and total SOD activity were measured in rat intestines following TLR9 inhibition and NOD receptor activation (Table III). The results indicated significantly elevated ROS production and reduced SOD activity in the SAP and NOD receptor activation groups ( $\mathrm{P}<0.05$, compared with the control group), and the NOD receptor activation group exhibited the greatest change in ROS and SOD levels ( $\mathrm{P}<0.05$, compared with the SAP group). The TLR9 inhibitor group significantly inhibited ROS production and elevated SOD activity $(\mathrm{P}<0.05$, compared with the SAP group). These results indicated that the NOD receptors and TLR9 may modulate SAP-induced intestinal injury via alteration of the oxidation/antioxidation balance.

\section{Discussion}

TLRs can recognize molecular markers from a wide range of pathogens. There are currently 11 known members of the TLR family with unique ligands. The endotoxin lipopolysaccharide from gram-negative bacteria can be recognized by TLR3, however, the major ligand of TLR9 is CpG-DNA $(18,19)$. Upon activation, TLR9 transduces signals via Toll-interleukin receptor structural domains to activate NF- $\mathrm{kB}$, thereby regulating gene transcription, inducing the release of inflammatory factors, such as TNF- $\alpha$ and IL-1 $\beta$, and leading to an increased inflammatory response (20). The NOD receptor family serves a similar function to the TLR family. Amongst these, NOD1 and NOD2 are associated with the induction of inflammation, with DAP and MDP as their ligands, respectively $(21,22)$. A recent study has revealed a correlation between NOD receptors and TLR or pancreatitis (23). The role and mechanism of the NOD receptor and TLR9 in SAP-induced intestinal injury, however, has not been elucidated. The present study established a SAP rat model, following by treatments with either NOD ligand agonists or a TLR9 inhibitor in order to investigate the impact of their activity modulation on serological and inflammatory factors. TLR9, NOD1 and NOD2 expression in the SAP and NOD receptor activation groups were significantly elevated, with the greatest effect observed in the NOD receptor activation group. The TLR9 inhibitor group exhibited decreased TLR9, NOD1 and NOD2 expression. These results suggested that TLR9 and NOD may have inter-regulatory effects on intestinal injury during SAP.

SAP commonly occurs in early MODS and late infectious necrosis (24), and the pathogenesis can facilitate the abundant release of inflammatory factors by lymphocytes, neutrophils and macrophages. The upregulation of anti-inflammatory factors further interferes with the pro-inflammatory/anti-inflammatory balance, eventually causing mortality as a result of SIRS and multiple organ failure (25). Therefore, a core explanation for SAP-related intestinal injury is induction of the inflammatory response. Furthermore, SAP can damage the liver, resulting in the release of enzymes synthesized by liver cells into the hepatic portal vein, from which they are distributed to the tissues and organs via the circulation, causing elevated serum AMY, $\mathrm{Cr}$ and ALT, and aggravating intestinal injury (26). The present study demonstrated that TLR9 and NOD receptor modulation may modify the inflammatory response via alterations to the serum inflammatory factor release in SAP. Regulation of these receptors may improve the serology index in early MODS of SAP, and potentially limit SAP pathogenesis and SAP-related intestinal injury.

The present study also investigated related inflammatory mechanisms, and demonstrated elevated ROS and decreased SOD levels during SAP pathogenesis. Under normal functioning of the cellular antioxidant system, ROS is continuously cleared, thus preventing and alleviating tissue injury. SOD is an important antioxidant enzyme involved in the clearance of free oxygen radicals, and serves an important role in maintaining the oxidation and antioxidation balance (27). Modulation of TLR9 and NOD receptor activity may impact upon the oxidation/antioxidation balance, as SOD upregulation will accelerate ROS clearance; therefore, regulation of TLR9 and NOD may potentially decrease SAP-related intestinal tissue injury. TLR and NOD receptor function as important innate immune receptors, and can recruit innate immune cells under pathogenic invasion, thus participating in the immune response. NF- $\mathrm{kB}$, as a target gene for facilitating expression and transcription, is a critical mediator (28). The present study 
demonstrated significantly elevated NF- $\mathrm{\kappa B}$ expression in rat intestinal tissues in SAP and NOD receptor groups, whilst TLR9 inhibition significantly depressed the intestinal expression of NF- $\mathrm{KB}$, suggesting that TLR9 and NOD may modulate SAP-related intestinal injury by regulating NF- $\mathrm{KB}$ expression in SAP.

In conclusion, the NOD1 and NOD2 receptors and TLR9 demonstrated an ability to regulate NF- $\mathrm{KB}$ expression and the oxidation/antioxidation balance to modulate the inflammatory response, which may affect SAP-related intestinal injury. The NOD receptors and TLR9 may function synergistically to accomplish this effect. The present study investigated the SAP-related intestinal injury at a molecular level, thus providing a molecular mechanism for the investigation of novel clinical treatments for SAP-related intestinal injury.

\section{References}

1. Gooshe M, Abdolghaffari AH, Nikfar S, Mahdaviani P and Abdollahi M: Antioxidant therapy in acute, chronic and post-endoscopic retrograde cholangiopancreatography pancreatitis: An updated systematic review and meta-analysis. World J Gastroenterol 21: 9189-9208, 2015.

2. Jiang DL, Yang J, Jiang SY, Yuan FL, Gu YL, Li JP and Pei ZJ: Modified Da Chengqi granules improvement in immune function in early severe acute pancreatitis patients. Genet Mol Res 15 2016.

3. Zhu Y, Yin H, Zhang R, Ye X and Wei J: Nasogastric nutrition versus nasojejunal nutrition in patients with severe acute pancreatitis: A meta-analysis of randomized controlled trials. Gastroenterol Res Pract 2016: 6430632, 2016.

4. Herath HM and Kulatunga A: Acute pancreatitis complicated with deep vein thrombosis and pulmonary embolism: A case report. J Med Case Rep 10: 182, 2016.

5. Kobayashi T, Miura K, Ishikawa H, Soma D, Zhang Z, Yuza K Hirose Y, Takizawa K, Nagahashi M, Sakata J, et al: Successful endoscopic management of acute necrotic pancreatitis and walled off necrosis after auxiliary partial orthotopic living-donor liver transplantation: A case report. Transplant Proc 48: 1212-1214, 2016.

6. Gorsky VA, Agapov MA, Khoreva MV and Leonenko IV: The effect of lornoxicam on TLR2 and TLR4 messenger RNA expression and tumor necrosis factor- $\alpha$, interleukin- 6 and interleukin-8 secretion in patients with systemic complications of acute pancreatitis. Pancreas 44: 824-830, 2015.

7. Matas-Cobos AM, Redondo-Cerezo E, Alegría-Motte C, Martínez-Chamorro A, Saenz-López P, Jiménez P, Jiménez MR González-Calvín JL, de Teresa J and Osuna FR: The role of Toll-like receptor polymorphisms in acute pancreatitis occurrence and severity. Pancreas 44: 429-433, 2015.

8. Takagi Y, Masamune A, Kume K, Satoh A, Kikuta K, Watanabe T, Satoh K, Hirota M and Shimosegawa T: Microsatellite polymorphism in intron 2 of human Toll-like receptor 2 gene is associated with susceptibility to acute pancreatitis in Japan. Hum Immunol 70: 200-294, 2009.

9. Caruso R and Núñez G: Innate immunity: ER stress recruits NOD1 and NOD2 for delivery of inflammation. Curr Biol 26: R508-R511, 2016.

10. He X, Wei Z, Wang J, Kou J, Liu W, Fu Y and Yang Z: Alpinetin attenuates inflammatory responses by suppressing TLR4 and NLRP3 signaling pathways in DSS-induced acute colitis. Sci Rep 6: 28370, 2016.

11. Zou Y, Lei W, He Z and Li Z: The role of NOD1 and NOD2 in host defense against chlamydial infection. FEMS Microbiol Lett 363: pii: fnw170, 2016.
12. Paria A, Deepika A, Sreedharan K, Makesh M, Chaudhari A, Purushothaman CS, Thirunavukkarasu AR and Rajendran KV: Identification of Nod like receptor C3 (NLRC3) in Asian seabass, lates calcarifer: Characterisation, ontogeny and expression analysis after experimental infection and ligand stimulation. Fish Shellfish Immunol 55: 602-612, 2016.

13. Albayrak S, Zengin K, Tanik S, Atar M, Unal SH, Imamoglu MA and Gurdal M: Can the neutrophil-to-lymphocyte ratio be used to predict recurrence and progression of non-muscle-invasive bladder cancer? Kaohsiung J Med Sci 32: 327-333, 2016.

14. Bobbala D, Orkhis S, Kandhi R, Ramanathan S and Ilangumaran S: Interleukin-21-dependent modulation of $\mathrm{T}$ cell antigen receptor reactivity towards low affinity peptide ligands in autoreactive CD8(+) T lymphocytes. Cytokine 85: 83-91, 2016.

15. Patin EC, Jones AV, Thompson A, Clement M, Liao CT, Griffiths JS, Wallace LE, Bryant CE, Lang R, Rosenstiel P, et al: IL-27 induced by select candida spp. via TLR7/NOD2 signaling and IFN- $\beta$ production inhibits fungal clearance. J Immunol 197: 208-221, 2016.

16. Kang LL, Zhang DM, Ma CH, Zhang JH, Jia KK, Liu JH, Wang $\mathrm{R}$ and Kong LD: Cinnamaldehyde and allopurinol reduce fructose-induced cardiac inflammation and fibrosis by attenuating CD36-mediated TLR4/6-IRAK4/1 signaling to suppress NLRP3 inflammasome activation. Sci Rep 6: 27460, 2016.

17. Livak KJ and Schmittgen TD: Analysis of relative gene expression data using real-time quantitative PCR and the 2(-Delta Delta C(T)) method. Methods 25: 402-408, 2001.

18. Suppiah A, Malde D, Arab T, Hamed M, Allgar V, Smith AM and Morris-Stiff G: The prognostic value of the neutrophil-lymphocyte ratio (NLR) in acute pancreatitis: Identification of an optimal NLR. J Gastrointest Surg 17: 675-681, 2013

19. Cen Y, Liu C, Li X, Yan Z, Kuang M, Su Y, Pan X, Qin R, Liu X, Zheng J and Zhou H: Artesunate ameliorates severe acute pancreatitis (SAP) in rats by inhibiting expression of pro-inflammatory cytokines and Toll-like receptor 4. Int Immunopharmacol 38: 252-260, 2016.

20. Zhong K: Curcumin mediates a protective effect via TLR-4/NF- $\kappa$ B signaling pathway in rat model of severe acute pancreatitis. Cell Biochem Biophys 73: 175-180, 2015.

21. Zou PF, Chang MX, Li Y, Xue NN, Li JH, Chen SN and Nie P: NOD2 in zebrafish functions in antibacterial and also antiviral responses via NF- $\kappa$ B and also MDA5, RIG-I and MAVS. Fish Shellfish Immunol 55: 173-185, 2016.

22. Khare S, Radian AD, Dorfleutner A and Stehlik C: Measuring NLR oligomerization I: Size exclusion chromatography, co-immunoprecipitation and cross-linking. Methods Mol Biol 1417: 131-143, 2016.

23. Vaz J and Andersson R: Intervention on toll-like receptors in pancreatic cancer. World J Gastroenterol 20: 5808-5817, 2014.

24. Al Mofleh IA: Severe acute pancreatitis: Pathogenetic aspects and prognostic factors. World J Gastroenterol 14: 675-684, 2008.

25. Jaffer U, Wade RG and Gourlay T: Cytokines in the systemic inflammatory response syndrome: A review. HSR Proc Intensive Care Cardiovasc Anesth 2: 161-175. 2010.

26. El-Sayed el SM, Mansour AM and Nady ME: Protective effects of pterostilbene against acetaminophen-induced hepatotoxicity in rats. J Biochem Mol Toxicol 29: 35-42. 2015.

27. Wang W, Ding XQ, Gu TT, Song L, Li JM, Xue QC and Kong LD: Pterostilbene and allopurinol reduce fructose-induced podocyte oxidative stress and inflammation via microRNA-377. Free Radic Biol Med 83: 214-226, 2015.

28. Wang C, Sun H, Song Y, Ma Z, Zhang G, Gu X and Zhao L: Pterostilbene attenuates inflammation in rat heart subjected to ischemia-reperfusion: Role of TLR4/NF- $\mathrm{kB}$ signaling pathway. Int J Clin Exp Med 8: 1737-1746, 2015. 